\title{
Dietary fibre fermentability but not viscosity elicited the 'second-meal effect' in healthy adult dogs
}

\author{
Ping Deng ${ }^{1}$, Alison N. Beloshapka ${ }^{1}$, Brittany M. Vester Boler ${ }^{1}$ and Kelly S. Swanson ${ }^{1,2,3 *}$ \\ ${ }^{1}$ Department of Animal Sciences, University of Illinois, 1207 West Gregory Drive, Urbana, IL 61801, USA \\ ${ }^{2}$ Division of Nutritional Sciences, University of Illinois, 1207 West Gregory Drive, Urbana, IL 61801, USA \\ ${ }^{3}$ Department of Veterinary Clinical Medicine, University of Illinois, 1207 West Gregory Drive, Urbana, IL 61801, USA \\ (Submitted 25 May 2012 - Final revision received 7 September 2012 - Accepted 17 December 2012 - First published online 4 February 2013)
}

\begin{abstract}
The present study evaluated the effects of fibre fermentability and viscosity in a morning meal on glucose, insulin and glucagon-like peptide-1 (GLP-1) responses to a glucose challenge later in the day in six healthy female dogs. For this purpose, two Latin square design experiments were performed. In Expt 1, dogs were fed a low-fibre (LF; 1\% Solka-Floc (International Fiber Corporation) and $1 \%$ soya hulls) diet, a low-fermentable fibre (LFF; $5 \%$ Solka-Floc (International Fiber Corporation) and 3\% soya hulls) diet or a high-fermentable fibre (HFF; $5 \%$ pectin and $3 \%$ short-chain fructo-oligosaccharides) diet. In Expt 2, dogs were fed a low-viscosity fibre ( $5 \%$ Solka-Floc (International Fiber Corporation) and 3\% soya hulls) diet, a moderate-viscosity fibre (MVF; $2 \%$ Solka-Floc (International Fiber Corporation), $2 \%$ soya hulls, $2 \%$ psyllium and $2 \%$ pectin) diet or a high-viscosity fibre (HVF; $4 \%$ psyllium and $4 \%$ pectin) diet. Dogs were fed at 08.00, 12.00 and 16.00 hours on days $1-6$ of each period. On day 7 , dogs were fed at 08.00 hours and then dosed with maltodextrin at 12.00 hours. Data were analysed to identify baseline and incremental AUC (IAUC) changes among the treatments. In Expt 1 , glucose IAUC $_{0-180 \text { min }}$ was lower $(P<0 \cdot 05)$ in dogs fed the HFF $v$. LF and LFF diets. Insulin and GLP-1 IAUC $0-180$ min were not affected. In Expt 2, baseline GLP-1 was greater $(P<0.005)$ and baseline insulin was lower $(P<0.05)$ in dogs fed the HVF $v$. MVF

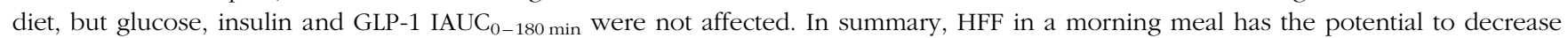
blood glucose response in a consequent meal.
\end{abstract}

Key words: Dietary fibres: Dogs: Second-meal effect: Glucagon-like peptide-1

Obesity is one of the most common diseases and is a risk factor for many co-morbidities in humans and companion animals, including diabetes mellitus. In dogs, obesity leads to altered blood lipids, glucose intolerance and insulin resistance $^{(1,2)}$, which is similar to humans. Many human and canine studies have highlighted the benefits of dietary fibre, especially soluble fibre, which results in decreased postprandial hyperglycaemia ${ }^{(3-5)}$, greater insulin sensitivity ${ }^{(6,7)}$ and altered gastrointestinal peptide release ${ }^{(8,9)}$. The efficacy of dietary fibre, however, differs according to the source, physical properties and fermentation capacity in the lower part of the gut ${ }^{(10)}$. For example, when dogs were fed a diet containing high-fermentable fibre (HFF, 6\% sugarbeet pulp, $2 \%$ gum arabic and $1.5 \%$ fructo-oligosaccharides) compared with that containing low-fermentable fibre (LFF, $7 \%$ cellulose), intestinal glucagon-like peptide-1 (GLP-1) secretion, which acts as an incretin hormone by stimulating insulin secretion, inhibiting glucagon secretion and delaying gastric emptying ${ }^{(11)}$, was increased and improved glucose homeostasis $^{(3)}$. In addition, the supplementation of shortchain fructo-oligosaccharides (scFOS) has been demonstrated to improve insulin sensitivity and modulate the transcription of genes involved in fatty acid or glucose metabolism in the adipose tissue of obese $\operatorname{dogs}{ }^{(7)}$.

In addition to the immediate postprandial effect that may occur, certain dietary fibres have also been shown to alter glycaemic response several hours later in a subsequent meal. The ability of an ingredient to affect a subsequent meal has been referred to as the 'second-meal effect'. In dogs, obesity causes insulin resistance ${ }^{(12)}$, which gives rise to hyperinsulinaemia and glucose intolerance ${ }^{(13)}$. Thus, fibres eliciting the second-meal effect may be used to improve postprandial hyperglycaemia in obese or diabetic dogs. Recent human studies have shown that evening meals rich in non-digestible carbohydrates decrease postprandial glucose to a high-glycaemic index breakfast ${ }^{(14-17)}$. The hypothesis is

Abbreviations: GLP-1, glucagon-like peptide-1; HFF, high-fermentable fibre; HVF, high-viscosity fibre; IAUC ${ }_{0-180 ~ m i n}$, incremental AUC $0-180$ min; LF, low fibre; LFF, low-fermentable fibre; LVF, low-viscosity fibre; MVF, moderate-viscosity fibre; scFOS, short-chain fructo-oligosaccharides. 
purported to be due to the SCFA (acetate, propionate and butyrate) produced by the fermentation of dietary fibre by the colonic microbiota. In general, SCFA may act directly on cells or receptors, through the action of gut hormones, or via other unknown mechanisms. There are several hypotheses of how SCFA may modulate glucose metabolism: (1) SCFA may increase insulin sensitivity by influencing adipocyte metabolism and decreasing lipolysis, resulting in decreased NEFA concentrations ${ }^{(18)}$; (2) butyrate and butyrate-associated factors play a possible role in moderating glucose-associated inflammation by modulating NF- $\mathrm{KB}$ activation ${ }^{(19)}$ and activating PPAR- $\gamma^{(20)}$; (3) propionate effects on hepatic carbohydrate metabolism to increase glucose use and decrease glucose production $^{(21)}$; (4) SCFA may up-regulate gene expression of the proglucagon gene to increase the secretion of GLP-1 and related peptides ${ }^{(22,23)}$. Because GLP-1 is known to delay gastric emptying $^{(24)}$ and stimulate insulin secretion ${ }^{(25,26)}$, it may contribute to the second-meal effect of fermentable dietary fibre consumption ${ }^{(27)}$. Due to decreased gastric emptying rates and delayed macronutrient digestion and absorption in the gastrointestinal tract ${ }^{(28)}$, diets rich in viscous dietary fibres may alter glucose and insulin responses immediately following a meal, but its effects on a subsequent meal are not known. The potential to elicit a second-meal effect probably depends on dietary fibre type and dosage. To our knowledge, there has not been previous research comparing the effects of dietary fibre fermentability and viscosity on the second-meal effect in dogs.

Dogs share many similarities with humans in terms of gastrointestinal anatomy and physiology. For example, dogs and humans have a strikingly similar stomach morphology, gastric emptying characteristics and postprandial hormone response ${ }^{(29,30)}$. Therefore, dogs are commonly used as a suitable human model for obesity and satiety studies and for testing the effects of diet on postprandial hormone and metabolite concentrations $^{(31-33)}$. The dog model allows for experiments whereby diet, food intake, feeding time, food preference, environment and exercise can be strictly controlled, and allows for repeated blood collections. The objective of the present study was to evaluate the effects of dietary fibre fermentability and viscosity fed in a morning meal on glucose, insulin and GLP-1 responses to a glucose challenge later in the day in healthy dogs. We hypothesised that the inclusion of fermentable (Expt 1) and viscous (Expt 2) fibres would elicit a second-meal effect, namely decreasing glycaemic response and increasing insulin and GLP-1 secretion, in response to an oral glucose load $4 \mathrm{~h}$ after their consumption.

\section{Materials and methods}

\section{Animals and diets}

A total of six healthy adult intact female hounds (age 5.0 (SEM $0 \cdot 1$ ) years; body weight 23.0 (Sem $2 \cdot 0) \mathrm{kg}$; body condition score on a nine-point scale $4.5-5.5)$ were used in these experiments. Dogs were individually housed in pens $(2.3 \mathrm{~m} \times 1.1 \mathrm{~m})$ in the animal facility of the Edward R. Madigan Laboratory at the University of Illinois. The room was environmentally controlled $\left(20^{\circ} \mathrm{C}\right)$ with a $16 \mathrm{~h}$ light $-8 \mathrm{~h}$ dark cycle. Dogs were allowed access to various toys for behavioural enrichment and to exercise outside of their cages and socialised with each other and humans for approximately $1 \mathrm{~h}$ at least $5 \mathrm{~d} /$ week except for collection days.

The dietary ingredient and chemical composition of six experimental diets are shown in Table 1. Based on previous in vitro fermentation experiments ${ }^{(34,35)}$ and digesta viscosity experiments ${ }^{(36)}$, dietary fibres were selected on their level of fermentability and viscosity. In Expt 1, dogs were randomly assigned to one of three treatments: a low-fibre (LF) diet containing 1\% Solka-Floc (International Fiber Corporation) and $1 \%$ soya hulls; a LFF diet containing 5\% Solka-Floc (International Fiber Corporation) and 3\% soya hulls; a HFF diet containing 5\% pectin (HM (high-methoxyl) Pectin; TIC Gums) and 3\% scFOS (SynergyC; BENEO-Group). In Expt 2, dogs were randomly assigned to one of three treatments: a low-viscosity fibre (LVF) diet containing 5\% Solka-Floc (International Fiber Corporation) and 3\% soya hulls; a moderate-viscosity fibre (MVF) diet containing 2\% Solka-Floc (International Fiber Corporation), 2\% soya hulls, 2\% psyllium (KV Vet Supply) and 2\% pectin; a high-viscosity fibre (HVF) diet containing $4 \%$ psyllium and $4 \%$ pectin. All the diets were formulated to meet all nutrient recommendations provided by the Association of American Feed Control Officials (2009) and were manufactured at Kansas State University's Bioprocessing and Industrial Value-Added Program facility (Manhattan, KS, USA) under the supervision of Pet Food \& Ingredient Technology, Inc. (Topeka, KS, USA). Dogs were fed to maintain body weight. Initial food intake was determined by calculating the maintenance energy requirement ${ }^{(37)}$ and by using previous feeding records. Dogs were weighed weekly and food intake was adjusted to maintain body weight and body condition score throughout the study. Water was available ad libitum throughout the experiment. All animal procedures were approved by the University of Illinois Institutional Animal Care and Use Committee before experimentation.

\section{Experimental design}

Dogs were fed the LF diet three times daily for 2 weeks before experimentation to allow for adaptation to the feeding pattern. The research was then conducted as two studies using a replicated $3 \times 3$ Latin square design. Each period in both experiments included a $6 \mathrm{~d}$ adaptation phase, followed by blood collection on day 7. Dogs were fed the experimental diets three times daily at 08.00, 12.00 and 16.00 hours on days 1-6. On day 7, dogs consumed their 08.00-hour meal as usual. At 12.00 hours, a baseline blood sample $(0 \mathrm{~min})$ was collected via jugular venepuncture. Following the baseline sample, $25 \mathrm{~g}$ maltodextrin in $120 \mathrm{ml}$ of water were administered using a $60 \mathrm{ml}$ syringe without a needle in place of their regular second meal. A maltodextrin solution, which is commonly used to test glycaemic and insulinaemic responses in humans and dogs, was given by dripping the solution from the syringe into the mouth of the dogs to ensure consumption within $10 \mathrm{~min}$. This method of dosing was done slowly to minimise stress 
Table 1. Ingredient and chemical composition of the experimental diets fed to dogs

\begin{tabular}{|c|c|c|c|c|c|c|}
\hline \multirow[b]{2}{*}{ Items } & \multicolumn{3}{|c|}{ Expt 1} & \multicolumn{3}{|c|}{ Expt 2} \\
\hline & LF & LFF & HFF & LVF & MVF & HVF \\
\hline \multicolumn{7}{|l|}{ Ingredient (\%, as-fed basis) } \\
\hline Brewer's rice & 35.00 & 29.00 & $29 \cdot 00$ & 29.00 & $29 \cdot 00$ & $29 \cdot 00$ \\
\hline Poultry by-product meal & $34 \cdot 30$ & 33.25 & 33.25 & $33 \cdot 25$ & 33.25 & 33.25 \\
\hline Maize, yellow, ground & $10 \cdot 00$ & $10 \cdot 00$ & $10 \cdot 00$ & $10 \cdot 00$ & $10 \cdot 00$ & 10.00 \\
\hline Poultry fat & 8.00 & 8.00 & 8.00 & 8.00 & 8.00 & 8.00 \\
\hline Maize gluten meal & 4.54 & 5.59 & 5.59 & 5.59 & 5.59 & 5.59 \\
\hline Egg product, dried & 4.00 & 4.00 & 4.00 & 4.00 & 4.00 & 4.00 \\
\hline Solka-Floc* & 1.00 & $5 \cdot 00$ & - & 5.00 & 2.00 & - \\
\hline Soya hulls, raw & 1.00 & 3.00 & - & 3.00 & 2.00 & - \\
\hline Pectin, HM rapid & - & - & 5.00 & - & 2.00 & 4.00 \\
\hline Psyllium & - & - & - & - & 2.00 & 4.00 \\
\hline scFOS & - & - & 3.00 & - & - & - \\
\hline Potassium chloride & 0.65 & 0.65 & 0.65 & 0.65 & 0.65 & 0.65 \\
\hline Salt & 0.65 & 0.65 & 0.65 & 0.65 & 0.65 & 0.65 \\
\hline Choline chloride & 0.50 & 0.50 & 0.50 & 0.50 & 0.50 & 0.50 \\
\hline Mineral premix $\dagger$ & $0 \cdot 18$ & 0.18 & 0.18 & 0.18 & 0.18 & 0.18 \\
\hline Vitamin premix $\ddagger$ & $0 \cdot 18$ & 0.18 & 0.18 & 0.18 & 0.18 & 0.18 \\
\hline \multicolumn{7}{|c|}{ Chemical composition (DM basis) } \\
\hline DM (\%) & 93.55 & 93.38 & 92.91 & 93.38 & 93.25 & 92.55 \\
\hline Protein (\%) & 34.61 & 33.88 & 33.81 & 33.88 & 32.09 & 32.39 \\
\hline Acid-hydrolysed fat (\%) & 17.83 & $18 \cdot 28$ & 17.99 & $18 \cdot 28$ & $17 \cdot 43$ & 16.08 \\
\hline TDF (\%) & 4.90 & $10 \cdot 48$ & $9.64 \S$ & $10 \cdot 48$ & $9 \cdot 71$ & $10 \cdot 15$ \\
\hline Ash (\%) & 6.05 & 5.88 & $5 \cdot 78$ & $5 \cdot 88$ & 5.88 & 5.94 \\
\hline Gross energy (kcal/g) & $5 \cdot 32$ & $5 \cdot 35$ & $5 \cdot 29$ & $5 \cdot 35$ & $5 \cdot 28$ & $5 \cdot 19$ \\
\hline Gross energy $(\mathrm{kJ} / \mathrm{g})$ & $22 \cdot 26$ & $22 \cdot 38$ & $22 \cdot 13$ & $22 \cdot 38$ & 22.09 & $21 \cdot 71$ \\
\hline
\end{tabular}

and avoid aspiration. Blood samples were then collected at 10, 20, 30, 45, 60, 90, 120 and 180 min after dosing.

\section{Chemical analyses}

Diet subsamples were collected and ground using a Wiley mill (Model 4; Thomas Scientific) through a $2 \mathrm{~mm}$ screen and dry ice in preparation for chemical analyses. Diet samples were analysed for DM and organic matter according to the Association of Official Analytical Chemists ${ }^{(38)}$. Crude protein was measured using a Leco Nitrogen/Protein Determinator (Model FP-2000, Leco Corporation) according to the Association of Official Analytical Chemists ${ }^{(38)}$. Fat concentrations were determined by acid hydrolysis according to the American Association of Cereal Chemists ${ }^{(39)}$ followed by diethyl ether extraction $^{(40)}$. Total dietary fibre was determined according to Prosky et al. ${ }^{(41)}$. Gross energy was measured using a bomb calorimeter (Model 1261; Parr Instrument Company).

\section{Blood collection and analysis}

The same blood collection and handling procedures for the measurement of serum glucose, serum insulin and plasma active GLP-1 were used in both experiments. A total of $6 \mathrm{ml}$ of blood were collected at each time point via jugular venepuncture using $10 \mathrm{ml}$ syringes. Then, one drop of blood from syringes was immediately used to measure glucose concentration using the glucose oxidase method (AlphaTRAK Blood Glucose Monitoring System; Abbott Laboratories). Another $2 \mathrm{ml}$ of blood were then immediately transferred into a precooled Vacutainer tube (no. 367835; Becton, Dickinson and Company) containing EDTA and $20 \mu \mathrm{l}$ dipeptidyl peptidase IV inhibitor $(10 \mu \mathrm{l} / \mathrm{ml}$ blood; Millipore), and centrifuged at $1000 \mathrm{~g}$ at $4^{\circ} \mathrm{C}$ for $10 \mathrm{~min}$ for the measurement of plasma active GLP-1. The remaining blood was transferred to a serum separator tube (no. 367985; Becton, Dickinson and Company) to allow clotting to occur, and then centrifuged at $1300 \mathrm{~g}$ at room temperature for $15 \mathrm{~min}$ for the measurement of serum insulin. After centrifugation, the supernatant was collected into its respective cryovial and stored at $-20^{\circ} \mathrm{C}$ (for serum) or $-80^{\circ} \mathrm{C}$ (for plasma) until further analysis.

Serum insulin was determined using a Rat Insulin Enzyme Immunoassay kit (Cayman Chemical). Plasma active GLP-1 concentration was analysed using a Glucagon-Like Peptide 1 (Active) ELISA kit (Millipore). Both methods have been validated for use in dogs previously ${ }^{(30,42)}$. 


\section{Statistical analyses}

For the baseline samples, data were analysed using the MIXED procedure of SAS 9.2 (SAS Institute, Inc.) for testing the main effect of experimental diet and including random effects of dog and period. For post-second-meal samples, all data were expressed as the incremental change from baseline (baseline subtracted) to minimise the differences in baseline concentrations among dogs, and then analysed using the MIXED procedure of SAS 9.2 (SAS Institute, Inc.) as repeated measures. The main effects of diet and time were tested and the diet $\times$ time interaction was evaluated if significant. Random effects of $\mathrm{dog}$ and period were included in the model. Means were separated for diets using the PDIFF statement in the MIXED procedure for individual time points after detecting a significant diet effect using SLICE/time. Incremental $\mathrm{AUC}_{0-180 \mathrm{~min}}\left(\mathrm{IAUC}_{0-180 \mathrm{~min}}\right)$ data were calculated using all positive peak areas using GraphPad Prism version 5.00 for Windows (GraphPad Software). Differences in the IAUC $_{0-180 \mathrm{~min}}$ of glucose, insulin and active GLP-1 among the dietary treatments were tested for significance using the MIXED procedure of SAS 9.2 (SAS Institute, Inc.). $P \leq 0.05$ was considered as significant and $P \leq 0 \cdot 10$ was considered as a trend.

\section{Results}

\section{Expt 1}

Baseline concentrations of glucose, insulin and active GLP-1 in Expt 1 were not affected $(P>0.05)$ by the dietary treatments (Table 2). Fig. 1 presents the incremental changes in glucose, insulin and active GLP-1 concentrations for $3 \mathrm{~h}$ after dosing with maltodextrin. In general, blood glucose concentration (Fig. 1(a)) peaked 20-30 min after dosing and then gradually decreased over time until approaching baseline at approximately $180 \mathrm{~min}$. In dogs fed the LF and LFF diets, the first peak was followed by another peak after 60-90 min. In contrast to dogs fed the HFF diet that had a sharp decrease in blood glucose from 60 to $90 \mathrm{~min}$, dogs fed the LF and LFF diets maintained high glucose levels throughout the $90 \mathrm{~min}$ postprandial period. Blood glucose concentration was lower $(P<0.05)$ during the HFF treatment compared with the LFF or LF treatment at $90 \mathrm{~min}$. Blood glucose during the LFF and LF treatments approached, but did not return to baseline by $180 \mathrm{~min}$. Incremental changes in blood insulin concentrations had the similar two-peak pattern among the dietary treatments (Fig. 1(b)). Insulin concentrations in dogs fed the HFF, LF and LFF diets returned to baseline at approximately 90, 120 and $180 \mathrm{~min}$, respectively. Active GLP-1 concentrations were highly variable throughout the $180 \mathrm{~min}$ postprandial period (Fig. 1(c)). Dogs fed the HFF and LF diets had GLP-1 peaks at $20 \mathrm{~min}$ that quickly dropped to baseline at approximately 90 min. Dogs fed the LFF diet, however, had a GLP-1 peak at $45 \mathrm{~min}$, which gradually decreased to baseline at $120 \mathrm{~min}$.

Because AUC values consider the entire postprandial curve, they are a better indicator of treatment response than individual time points. Dogs fed the HFF diet had lower $(P=0 \cdot 049)$ postprandial glucose IAUC $_{0-180 \text { min }}$ when compared with

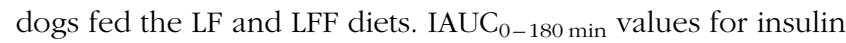
and active GLP-1 were not different among the dietary treatments. Fasting basal insulin:glucose ratio and $\mathrm{AUC}_{\text {insulin: }}$ $\mathrm{AUC}_{\text {glucose }}$ did not differ among the test diets (Table 2).

\section{Expt 2}

Baseline glucose concentrations did not differ $(P>0.05)$ among dogs fed the LVF, MVF and HVF diets (Table 3 ). Baseline GLP-1 concentrations were greater $(P=0 \cdot 005)$ in dogs fed the HVF diet, while baseline insulin concentrations in dogs fed the HVF diet tended to be lower $(P \leq 0 \cdot 10)$ than dogs fed the MVF diet.

Fig. 2 presents the incremental changes in glucose, insulin and active GLP-1 concentrations for $3 \mathrm{~h}$ after dosing with maltodextrin. Blood glucose concentration (Fig. 2(a)) peaked $20-45 \mathrm{~min}$ after dosing and then gradually decreased over time. In dogs fed the HVF and MVF diets, the first peak was followed by another peak at approximately $60 \mathrm{~min}$ and then the glucose concentration approached, but did not return to baseline by $180 \mathrm{~min}$. However, dogs fed the

Table 2. Serum glucose, insulin and plasma active glucagon-like peptide-1 (GLP-1) concentrations in dogs fed a low-fibre (LF), low-fermentable fibre (LFF) or high-fermentable fibre (HFF) diet

(Mean values with their standard errors, $n 6$ )

\begin{tabular}{|c|c|c|c|c|c|}
\hline \multirow[b]{2}{*}{ Items } & \multicolumn{3}{|c|}{ Treatments } & \multirow[b]{2}{*}{ SEM } & \multirow[b]{2}{*}{$P$} \\
\hline & LF & LFF & HFF & & \\
\hline \multicolumn{6}{|l|}{ Baseline concentration } \\
\hline Glucose (mg/l) & 1042 & 1028 & 1130 & 41 & 0.106 \\
\hline Insulin (pmol/l) & $135 \cdot 3$ & $108 \cdot 0$ & $161 \cdot 2$ & $28 \cdot 9$ & 0.169 \\
\hline GLP-1 (pmol/l) & $7 \cdot 8$ & $6 \cdot 8$ & $9 \cdot 1$ & $1 \cdot 7$ & 0.610 \\
\hline Insulin:glucose* & 0.13 & $0 \cdot 10$ & 0.14 & 0.02 & 0.150 \\
\hline \multicolumn{6}{|l|}{$\mathrm{IAUC}_{0-180 \mathrm{~min}}$} \\
\hline Glucose (mg/l) & $40700^{a, b}$ & $45620^{a}$ & $30050^{b}$ & 5870 & 0.049 \\
\hline Insulin (pmol/l) & 10027 & 15110 & 12033 & 2737 & 0.453 \\
\hline GLP-1 (pmol/l) & 401 & 506 & 319 & 124 & 0.501 \\
\hline$A \cup C_{\text {insulin }}: A \cup C_{\text {glucose }} \dagger$ & 0.23 & 0.35 & 0.41 & 0.08 & 0.358 \\
\hline
\end{tabular}

IAUC, incremental AUC.

a,b Mean values within a row with unlike superscript letters were significantly different $(P \leq 0 \cdot 05)$.

${ }^{*}$ Fasting basal insulin:glucose ratio.

† Ratio of area under the insulin:glucose curve. 


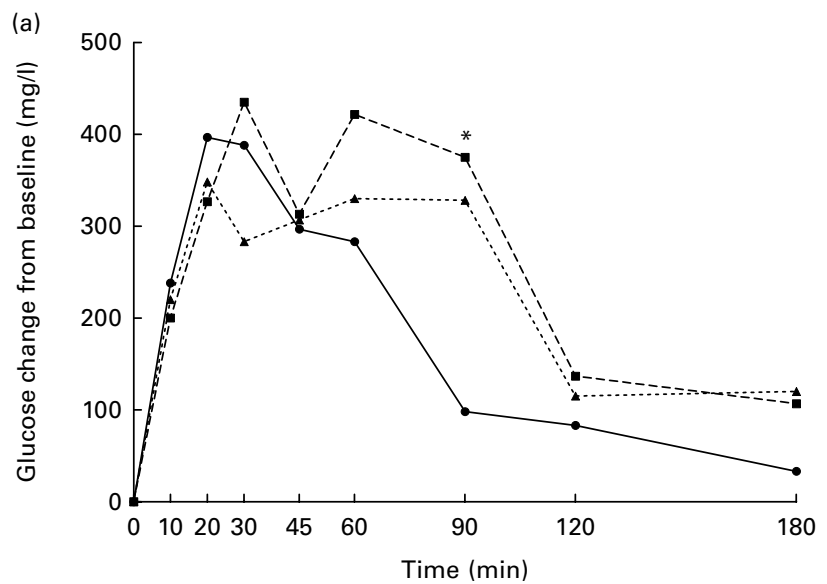

(b)
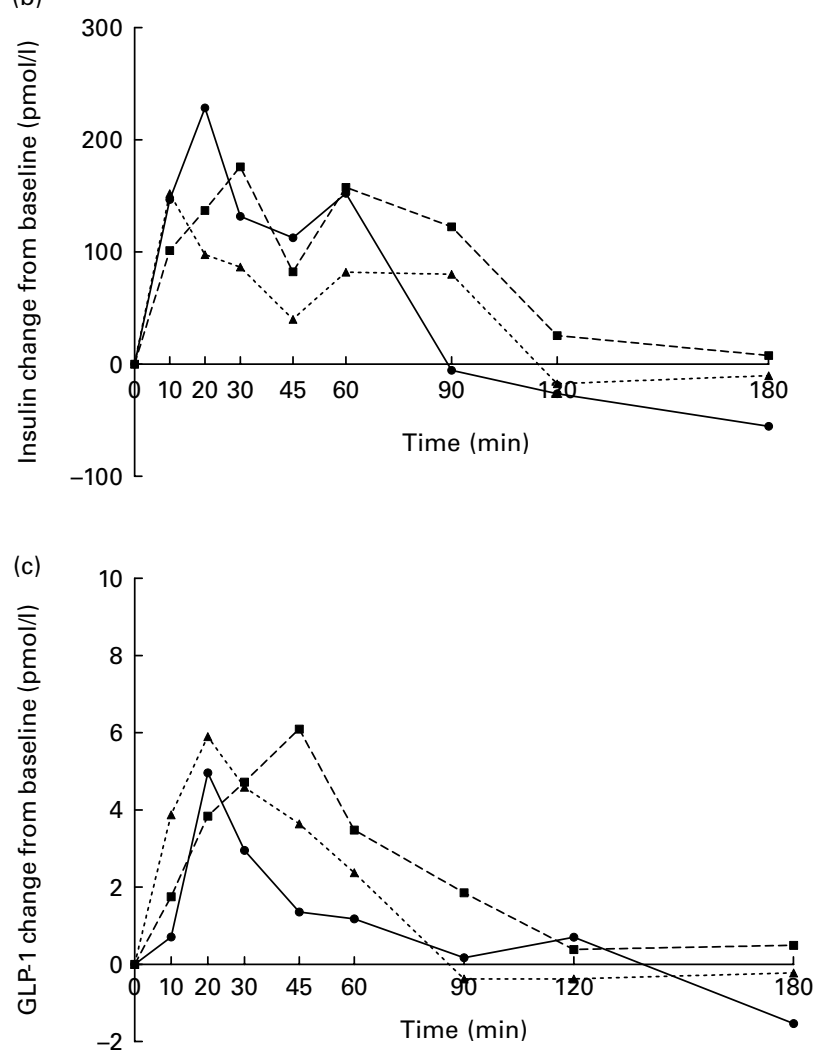

Fig. 1. Incremental changes in (a) serum glucose, (b) serum insulin and (c) plasma active glucagon-like peptide-1 (GLP-1) concentrations in dogs fed a low-fibre (- - ), low-fermentable fibre (- $)$ or high-fermentable fibre (-) diet in Expt 1. Values are incremental changes from baseline means. (a) SEM $=5.25$; diet, $P=0.288$; time, $P<0.0001$; diet $\times$ time, $P=0.116$. * Mean values were significantly different among the dietary treatments $(P<0.05)$. (b) $\mathrm{SEM}=40.85$; diet, $P=0.356$; time, $P<0.0001$; diet $\times$ time, $P=0.424$. (c) SEM $=1.49$; diet, $P=0.575$; time, $P<0.0001$; diet $\times$ time, $P=0.457$.

LVF diet had a sharp decrease in glucose concentration after $90 \mathrm{~min}$, which returned to baseline at approximately $120 \mathrm{~min}$. Incremental changes in blood insulin concentrations had the similar two-peak pattern among the dietary treatments (Fig. 2(b)). Insulin concentrations in dogs fed the HVF, MVF and LVF diets returned to baseline at approximately 180, 90 and $120 \mathrm{~min}$, respectively. Incremental changes in active
GLP-1 concentrations were highly variable throughout the 180 min postprandial period (Fig. 2(c)). GLP-1 concentration in the MVF treatment had a sharp peak at $20 \mathrm{~min}(P=0.006)$ that quickly dropped near the baseline at $45 \mathrm{~min}$ and did not change over time after $45 \mathrm{~min}$. GLP-1 incremental change in the HVF treatment peaked at approximately $30 \mathrm{~min}$, and then remained at a lower level after $60 \mathrm{~min}$. Dogs fed the LVF diet had a GLP-1 peak at $10 \mathrm{~min}$, but thereafter neither changed over time nor returned to baseline. No dietary treatment effects were observed in the postprandial IAUC $_{0-180 \mathrm{~min}}$ of glucose, insulin and active GLP-1. Fasting basal insulin: glucose ratio and $\mathrm{AUC}_{\text {insulin }}: \mathrm{AUC}_{\text {glucose }}$ did not differ among the test diets (Table 3).

\section{Discussion}

In the early twentieth century, Staub ${ }^{(43)}$ and Traugott ${ }^{(44)}$ first reported the second-meal effect. In these human studies, they demonstrated that an initial glucose load decreased glycaemic response of a second glucose load within $12 \mathrm{~h}$. Recently, due to the prevalence of obesity and diabetes, the benefit of the second-meal effect has drawn much wider attention. However, the mechanisms involved in the second-meal effect are still unclear. In human subjects, consumption of a low-glycaemic index food in an evening meal has been shown to improve postprandial glucose response during breakfast the next morning. Indeed, these low-glycaemic index foods contain a source of dietary fibre. Dietary fibres are broadly classified into soluble and insoluble forms based on their solubility in water. Fibres may also be classified as viscous $v$. non-viscous fibre and fermentable $v$. non-fermentable fibre according to their physico-chemical properties and physiological effects on the host. Until now, there has been no research comparing the effects of dietary fibre type or amount on the second-meal effect. The present study aimed to evaluate the effects of dietary fibre type and amount on the second-meal effect in the dog model.

In the present study, all dogs were fed the dry kibble experimental diets at amounts to maintain body weight and body condition score. Feeding three times daily was used to mimic a human eating pattern, yet staying within the practical limits of conducting an in vivo experiment. Data from the present study, therefore, may be applied to both companion animal and human health.

The aim of the first experiment was to evaluate the secondmeal effect of diets containing varying amounts of fermentable fibre. We hypothesised that because a morning meal containing fermentable fibre would increase SCFA production in the colon, it would subsequently modulate postprandial blood glucose and insulin peaks and incremental AUC following an oral glucose load provided $4 \mathrm{~h}$ later. We observed that when the HFF diet including 5\% pectin and 3\% scFOS was consumed in the morning, a decreased blood glucose response resulted during the oral glucose load at noon. This occurred without altering the baseline glucose, insulin and GLP-1 concentrations or postprandial insulin or GLP-1 response. The LF and LFF diets did not alter the glucose, insulin or GLP-1 response after the oral glucose load. Although 
Table 3. Serum glucose, insulin and plasma active glucagon-like peptide-1 (GLP-1) concentrations in dogs fed a low-viscosity fibre (LVF), moderate-viscosity fibre (MVF) or high-viscosity fibre (HVF) diet

(Mean values with their standard errors, $n 6$ )

\begin{tabular}{|c|c|c|c|c|c|}
\hline \multirow[b]{2}{*}{ Items } & \multicolumn{3}{|c|}{ Treatments } & \multirow[b]{2}{*}{ SEM } & \multirow[b]{2}{*}{$P$} \\
\hline & LVF & MVF & HVF & & \\
\hline \multicolumn{6}{|l|}{ Baseline concentration } \\
\hline Glucose (mg/l) & 1133 & 1098 & 1090 & 39 & 0.299 \\
\hline Insulin (pmol/l) & 138.9 & $166 \cdot 4$ & $126 \cdot 6$ & $40 \cdot 8$ & 0.102 \\
\hline GLP-1 (pmol/l) & $7 \cdot 3^{\mathrm{a}}$ & $8 \cdot 3^{a}$ & $16 \cdot 6^{\mathrm{b}}$ & 2.5 & 0.005 \\
\hline Insulin:glucose* & 0.12 & 0.15 & $0 \cdot 12$ & 0.04 & 0.124 \\
\hline \multicolumn{6}{|l|}{$\mathrm{IAUC}_{0-180 \mathrm{~min}}$} \\
\hline Glucose (mg/l) & 27910 & 33730 & 35540 & 7640 & 0.332 \\
\hline Insulin (pmol/l) & 9066 & 10271 & 13905 & 4004 & 0.436 \\
\hline GLP-1 (pmol/l) & 586 & 447 & 487 & 144 & 0.788 \\
\hline$A \cup C_{\text {insulin }}: A \cup C_{\text {glucose }} \uparrow$ & 0.29 & 0.34 & 0.40 & $0 \cdot 10$ & 0.580 \\
\hline
\end{tabular}

IAUC, incremental AUC.

${ }^{a, b}$ Mean values within a row with unlike superscript letters were significantly different $(P \leq 0.05)$

${ }^{*}$ Fasting basal insulin:glucose ratio.

$\dagger$ Ratio of area under the insulin:glucose curve.

baseline insulin:glucose concentrations and insulin AUC: glucose AUC were not different $(P>0.05)$, these results indicate that HFF diets may have the potential to increase insulin secretory response or insulin sensitivity in dogs. A previous study in human subjects has also reported that cooked barley kernels, which contain fermentable fibre, increased insulin sensitivity and decreased blood glucose response ${ }^{(17)}$. Studies have also confirmed that the colonic fermentation of scFOS specifically can increase insulin sensitivity ${ }^{(7,45)}$. Shinoki \& Hara ${ }^{(45)}$ demonstrated that rats fed scFOS had increased insulin sensitivity, reduced large-intestinal fat mass and reduced leptin secretion from the mesenteric adipocytes of the small intestine. Adding $1 \%$ scFOS to the diet of obese dogs decreased insulin resistance and appeared to modulate the transcription of genes involved in fatty acid metabolism ${ }^{(7)}$. Although there has not been research studying the effect of pectin on the insulin sensitivity of dogs, both scFOS and pectin are highly fermentable in the colon by the microbiota, yielding SCFA that are thought to be an important mediator of these effects.

Several mechanisms by which SCFA may mediate the second-meal effect have been postulated. First, SCFA may influence glucose response through increasing GLP-1 secretion. Reimer et al. ${ }^{(46)}$ reported that mRNA abundance of proglucagon, the precursor of GLP-1, was increased in rats fed fermentable fibre-containing diets. Massimino et al. ${ }^{(3)}$ also reported an increased proglucagon mRNA and plasma GLP-1 AUC in adult dogs fed diets high in fermentable fibre $v$. low-fermentable fibre. Nilsson et al. ${ }^{(16)}$ reported that an evening meal with barley kernels resulted in a higher GLP-1 $\mathrm{AUC}_{0-120 \text { min }}$ after the following breakfast than the evening meal with white wheat. In addition, GLP-1 and glucose responses after the following breakfast were inversely related $^{(16)}$. However, in the present study, we did not observe differences among the dietary treatments in either baseline or postprandial GLP-1 response following a glucose load at the second meal. Second, SCFA may affect the gastric emptying rate. Brighenti et al. ${ }^{(14)}$ reported that a high-glycaemic index meal supplemented with fermentable disaccharide lactulose improved glucose tolerance, accompanied with a lower NEFA concentration and a slower gastric emptying rate at the second-meal time. This delay in gastric emptying could be the effect of SCFA via GLP-1, but contradictory results are present in the literature. Data reported by Priebe et al. ${ }^{(17)}$ do not suggest that the second-meal effect is due to SCFA mediation of gastric emptying. Those researchers observed a higher glucose clearance rate (suggesting increased uptake into peripheral tissues) in the fermentable fibre treatment, but no difference in the rate of exogenous glucose appearance.

Although many SCFA-related effects may function through GLP-1, other possible mechanisms are GLP-1 independent. A third potential mechanism by which SCFA may mediate the second-meal effect is by increasing insulin sensitivity by influencing adipocyte metabolism ${ }^{(18)}$. It has been shown that an evening meal containing barley can reduce serum NEFA concentrations measured the next morning ${ }^{(47)}$. Increased NEFA due to oxidative stress or some other mechanism are closely linked to insulin resistance ${ }^{(45,46)}$. In contrast, suppression of NEFA release increases the body's ability to take up glucose, allowing a greater storage of glucose as muscle glycogen ${ }^{(48)}$. SCFA may also improve glucose tolerance and insulin sensitivity by influencing carbohydrate metabolism ${ }^{(49,50)}$. Venter et al. ${ }^{(49)}$ reported that propionate supplementation decreased fasting serum glucose and maximum insulin increments during glucose tolerance tests. These data were in line with that reported by Todesco et al. ${ }^{(50)}$, who demonstrated that dietary propionate supplementation in bread reduced the blood glucose area in comparison with standard propionatefree bread in healthy subjects. SCFA may mediate the second-meal effect by decreasing inflammatory markers. Priebe et $a l .{ }^{(17)}$ reported that an evening meal containing cooked barley kernels prevented the postprandial rise in the pro-inflammatory cytokines IL- 6 and TNF- $\alpha$ after the glucose load in the morning. Mechanisms by which SCFA may contribute to reduced inflammation include the modulation of 
(a)
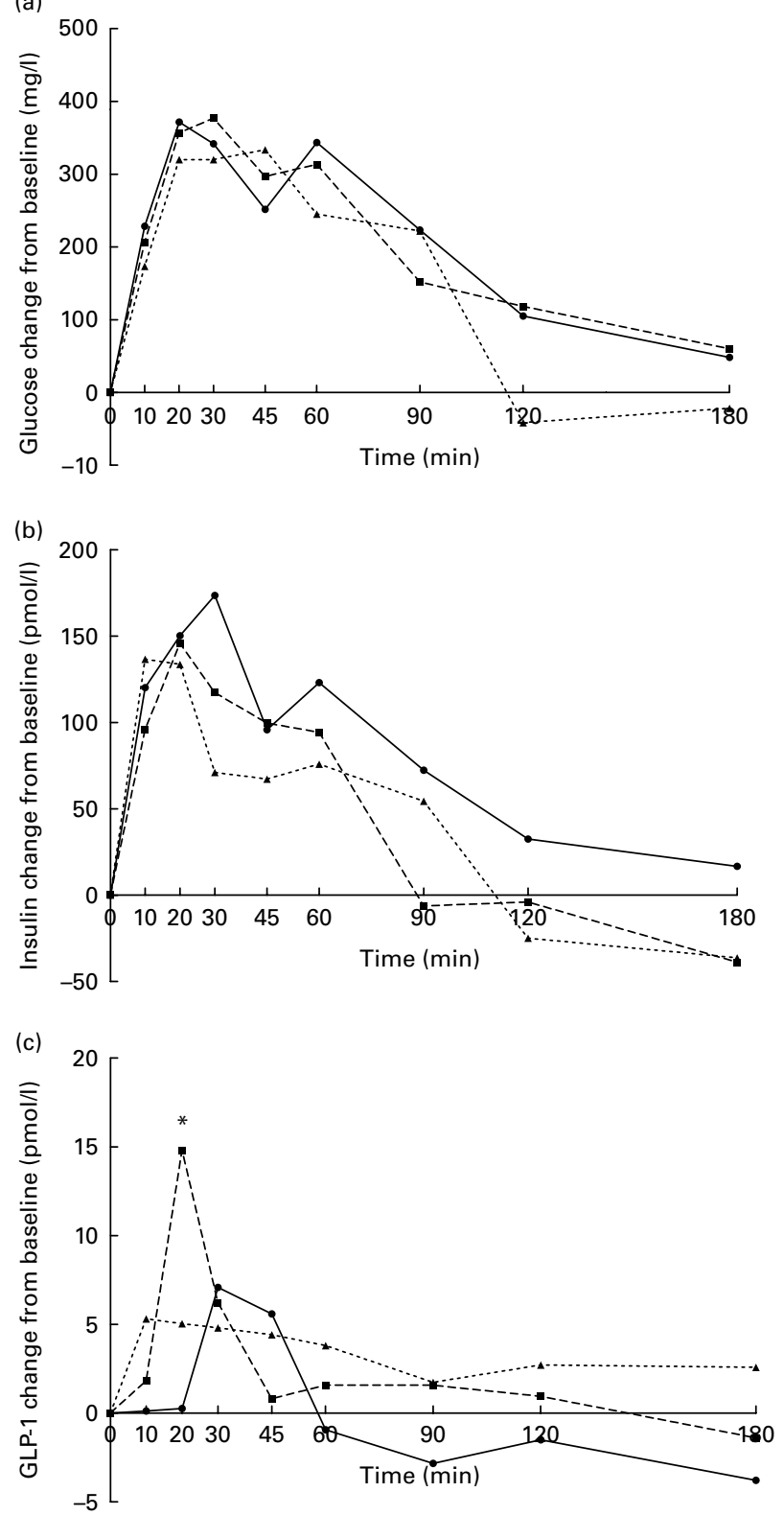

Fig. 2. Incremental changes in (a) serum glucose, (b) serum insulin and (c) plasma active glucagon-like peptide-1 (GLP-1) concentrations in dogs fed a low-viscosity fibre (-4), moderate-viscosity fibre (-m) or high-viscosity fibre (-) diet in Expt 2. Values are incremental changes from baseline means. (a) SEM $=6.36$; diet, $P=0.475$; time, $P<0.0001$; diet $\times$ time, $P=0.706$. (b) SEM $=39.50$; diet, $P=0.100$; time, $P<0.0001$; diet $\times$ time, $P=0.914$. (c) $\mathrm{SEM}=3.21$; diet, $P=0.154$; time, $P=0.059$; diet $\times$ time, $P=0.572$. ${ }^{*}$ Mean values were significantly different among the dietary treatments $(P<0.05)$.

$\mathrm{NF}-\kappa \mathrm{B}^{(19)}$ and the up-regulation of PPAR- $\gamma^{(20)}$. Although acetate, propionate and butyrate are the main SCFA produced via microbial fermentation, the ratios of SCFA may differ depending on the substrate (i.e. fibre source). In the present study, fibre mixtures were used, so such effects could not be tested. Because fibre source may have an impact on SCFA profiles and consequent physiological effects on the host, further study is needed to determine how specific fibre sources may affect these potential mechanisms and the second-meal effect.
Although it often affects glycaemic response in the meal at which it is consumed, it is unknown whether viscous fibres have the ability to affect glycaemic response in a second meal. It is possible and may have contributed in previous studies, but viscosity is difficult to measure and is not always distinguished from non-viscous fibres in such studies. In the second experiment of the present study, the aim was to evaluate the second-meal effect of diets containing highly or lowly viscous fibres by including variable amounts of psyllium, pectin and cellulose in the diets. We hypothesised that due to the delayed gastric emptying, macronutrient digestion and absorption in the gastrointestinal tract ${ }^{(28)}$, diets causing increased digesta viscosity would also modulate glucose and insulin responses following a glucose load $4 \mathrm{~h}$ later. The present data, however, suggest that supplementing 4 or $8 \%$ of viscous fibres in the morning meal does not influence postprandial glucose or insulin response (IAUC ${ }_{0-180 \mathrm{~min}}$ ) during the oral glucose load at the second-meal time. However, because baseline concentrations were different before the glucose load, any potential second-meal effects may have been masked in this experiment. Given the gastric emptying data that exist for dogs ${ }^{(51)}$, we expected a considerable proportion of the morning meal to reach the hindgut after $4 \mathrm{~h}$. This time was selected to represent a logical meal sequence for humans or dogs eating multiple meals each day. Because baseline differences were observed, more time after the morning meal may have been needed before the glucose tolerance test. Interestingly, when comparing the two experiments, HFF ( $5 \%$ pectin and $3 \%$ scFOS) decreased the postprandial glucose response at the second-meal time, while HVF ( $4 \%$ pectin and $4 \%$ psyllium) did not. Because pectin was included in both fermentable and viscous fibre diets, it may not contribute to the second-meal effect independently. In agreement with the present results, Pouteau et al. ${ }^{(52)}$ recently reported that a chronic 5-week ingestion of apple pectin and acacia gum blend had no effect on glycaemia or lipidaemia, and did not improve the peripheral insulin sensitivity measured by the euglycaemic and hyperinsulinaemic clamp technique in patients with the metabolic syndrome.

Factors other than fermentation or viscosity may also improve postprandial glucose response, although mechanisms are unclear. In healthy women, for example, Weickert et $a l .{ }^{(53)}$ observed an improved postprandial glucose response during lunch in those that ingested bread containing a nonfermentable, insoluble wheat fibre $v$. white bread at breakfast. Weickert \& Pfeiffer ${ }^{(54)}$ postulated that other unknown mechanisms contributing to beneficial effects of insoluble dietary fibre consumption could involve increased insulin sensitivity, a shift in the relationship of gut microbiotic communities, as well as direct and indirect influences on yet unknown hormonal and molecular factors in the host.

In the present study, although we did not observe a secondmeal difference in GLP-1 IAUC $_{0-180 \mathrm{~min}}$ among the three diets differing in viscosity, baseline GLP-1 concentrations were greater $(P=0.005)$ in dogs fed the HVF diet. Because viscous diets may delay gastric emptying and intestinal transit, the time between the first and second meals may have not been long enough to appropriately test this effect. It has been 
reported that viscous dietary fibres may decrease the early postprandial GLP-1 response in healthy human subjects ${ }^{(9,55)}$. Karhunen et al. $^{(9)}$ reported that the postprandial GLP-1 concentration was significantly suppressed after a psyllium fibreand protein-rich meal, in contrast to the initial increase following the low-fibre/low-protein, high-fibre/low-protein and lowfibre/high-protein meals. The GLP-1 data in that study represented a $2 \mathrm{~h}$ response after meals ${ }^{(9)}$. Hooda et al. ${ }^{(56)}$ measured the postprandial GLP-1 response in $8 \mathrm{~h}$ in pigs when fed diets containing different levels of oat $\beta$-glucan and reported that GLP-1 was affected by time. Pigs fed a high-viscous fibre diet had lower GLP-1 concentrations at 90, 120 and $180 \mathrm{~min}$ postprandial than pigs fed low-viscous fibre diets. At $4 \mathrm{~h}$ postprandial, however, GLP-1 tended to increase in the high-viscous fibre treatment when compared with the low-viscous fibre treatments ${ }^{(56)}$.

In conclusion, the present results suggest that highly fermentable fibres have the potential to decrease blood glucose response in a meal fed many hours later, possibly by increasing insulin sensitivity in dogs. Viscous fibres, however, did not appear to contribute to a second-meal effect in dogs, but may have been masked by the timing of our meals. These findings provide valuable information that may be used as a platform for which to design subsequent studies targeting the secondmeal effect and its application to obese dog and human nutritional strategies. Further studies in dogs or human subjects may provide new insights into the mechanisms by which dietary fibres contribute to the second-meal effect.

\section{Acknowledgements}

The present study was supported by the ILSI North America Future Leader Award. K. S. S. designed the experiment. P. D., A. N. B. and B. M. V. B. performed the animal trials and laboratory analyses. P. D. performed the statistical analyses and wrote the manuscript. The authors sincerely thank Brenda Knapp, Katie Kerr, Kathleen Barry, Kim Cephas, Krasae Kanakupt, Laura Bauer, Marcial Guevara, Mariana Rossoni, Mindy Bozych, Ryan Grant and Trevor Faber involved in the sample collection. All authors declare that there are no conflicts of interest.

\section{References}

1. Mattheeuws D, Rottiers R, Baeyens D, et al. (1984) Glucosetolerance and insulin-response in obese dogs. J Am Anim Hosp Assoc 20, 287-293.

2. Chikamune T, Katamoto H, Ohashi F, et al. (1995) Serum lipid and lipoprotein concentrations in obese dogs. $J$ Vet Med Sci 57, 595-598.

3. Massimino SP, McBurney MI, Field CJ, et al. (1998) Fermentable dietary fiber increases GLP-1 secretion and improves glucose homeostasis despite increased intestinal glucose transport capacity in healthy dogs. J Nutr 128, 1786-1793.

4. Chandalia M, Garg A, Lutjohann D, et al. (2000) Beneficial effects of high dietary fiber intake in patients with type 2 diabetes mellitus. N Engl J Med 342, 1392-1398.

5. Giacco R, Parillo M, Rivellese AA, et al. (2000) Long-term dietary treatment with increased amounts of fiber-rich low-glycemic index natural foods improves blood glucose control and reduces the number of hypoglycemic events in type 1 diabetic patients. Diabetes Care 23, 1461-1466.

6. Pereira MA, Jacobs DR Jr, Pins JJ, et al. (2002) Effect of whole grains on insulin sensitivity in overweight hyperinsulinemic adults. Am J Clin Nutr 75, 848-855.

7. Respondek F, Swanson KS, Belsito KR, et al. (2008) Shortchain fructooligosaccharides influence insulin sensitivity and gene expression of fat tissue in obese dogs. $J$ Nutr 138, 1712-1718.

8. Cani PD, Lecourt E, Dewulf EM, et al. (2009) Gut microbiota fermentation of prebiotics increases satietogenic and incretin gut peptide production with consequences for appetite sensation and glucose response after a meal. Am J Clin Nutr $\mathbf{9 0}$, $1236-1243$.

9. Karhunen LJ, Juvonen KR, Flander SM, et al. (2010) A psyllium fiber-enriched meal strongly attenuates postprandial gastrointestinal peptide release in healthy young adults. J Nutr 140, 737-744.

10. Delzenne NM \& Cani PD (2005) A place for dietary fibre in the management of the metabolic syndrome. Curr Opin Clin Nutr Metab Care 8, 636-640.

11. Holst JJ (1997) Enteroglucagon. Annu Rev Physiol 59 , 257-271.

12. Rocchini AP, Mao HZ, Babu K, et al. (1999) Clonidine prevents insulin resistance and hypertension in obese dogs. Hypertension 33, 548-553.

13. Mattheeuws D, Rottiers R, Kaneko JJ, et al. (1984) Diabetes mellitus in dogs: relationship of obesity to glucose tolerance and insulin response. Am J Vet Res 45, 98-103.

14. Brighenti F, Benini L, Del Rio D, et al. (2006) Colonic fermentation of indigestible carbohydrates contributes to the second-meal effect. Am J Clin Nutr 83, 817-822.

15. Nilsson AC, Ostman EM, Preston T, et al. (2008) Effects of GI $v s$ content of cereal fibre of the evening meal on glucose tolerance at a subsequent standardized breakfast. Eur J Clin Nutr 62, 712-720.

16. Nilsson AC, Ostman EM, Holst JJ, et al. (2008) Including indigestible carbohydrates in the evening meal of healthy subjects improves glucose tolerance, lowers inflammatory markers, and increases satiety after a subsequent standardized breakfast. J Nutr 138, 732-739.

17. Priebe MG, Wang H, Weening D, et al. (2010) Factors related to colonic fermentation of nondigestible carbohydrates of a previous evening meal increase tissue glucose uptake and moderate glucose-associated inflammation. Am J Clin Nutr 91, 90-97.

18. Robertson DM (2007) Metabolic cross talk between the colon and the periphery: implications for insulin sensitivity. Proc Nutr Soc 66, 351-361.

19. Segain JP, Raingeard de la Bletiere D, Bourreille A, et al. (2000) Butyrate inhibits inflammatory responses through NF-kappa B inhibition: implications for Crohn's disease. Gut 47, 397-403.

20. Kinoshita M, Suzuki Y \& Saito Y (2000) Butyrate reduces colonic paracellular permeability by enhancing PPAR gamma activation. Biochem Biophys Res Commun 293, $827-831$.

21. Anderson JW \& Bridges SR (1984) Short-chain fatty acid fermentation products of plant fiber affect glucose metabolism of isolated rat hepatocytes. Proc Soc Exp Biol Med 177, 372-376.

22. Reimer RA \& McBurney MI (1996) Dietary fiber modulates intestinal proglucagon messenger ribonucleic acid and postprandial secretion of glucagon-like peptide-1 and insulin in rats. Endocrinology 137, 3948-3956. 
23. Drozdowski LA, Dixon WT, McBurney MI, et al. (2002) Short-chain fatty acids and total parenteral nutrition affect intestinal gene expression. J Parenter Enteral Nutr 26, $145-150$

24. Schirra J, Kuwert P, Wank U, et al. (1997) Differential effects of subcutaneous GLP-1 on gastric emptying, antroduodenal motility, and pancreatic function in men. Proc Assoc Am Phys 109, 84-97.

25. Kreymann B, Williams G, Ghatei MA, et al. (1987) Glucagonlike peptide-1 7-36: a physiological incretin in man. Lancet ii, $1300-1304$

26. Burcelin R, Cani PD \& Knauf C (2007) Glucagon-like peptide-1 and energy homeostasis. J Nutr 137, 2534S-2538S.

27. Dupre J, Behme MT, Hramiak IM, et al. (1995) Glucagon-like peptide I reduces postprandial glycemic excursions in IDDM. Diabetes 44, 626-630.

28. Pereira MA \& Ludwig DS (2001) Dietary fiber and bodyweight regulation. Observations and mechanisms. Pediatr Clin North Am 48, 969-980.

29. Kararli TT (1995) Comparison of the gastrointestinal anatomy, physiology, and biochemistry of humans and commonly used laboratory animals. Biopharm Drug Dispos 16, 351-380.

30. Lubbs DC, Vester Boler BM, Ridge TK, et al. (2010) Dietary macronutrients and feeding frequency affect fasting and postprandial concentrations of hormones involved in appetite regulation in adult dogs. J Anim Sci 88, 3945-3953.

31. Rees DA \& Alcolado JC (2005) Animal models of diabetes mellitus. Diabet Med 22, 359-370.

32. Knapp BK, Parsons CM, Bauer LL, et al. (2010) Soluble fiber dextrins and pullulans vary in extent of hydrolytic digestion in vitro and in energy value and attenuate glycemic and insulinemic responses in dogs. J Agric Food Chem 58, 11355-11363.

33. Vester Boler BM, Faber TA, Bauer LL, et al. (2012) Acute satiety response of mammalian, avian and fish proteins in dogs. Br J Nutr 107, 146-154

34. Sunvold GD, Fahey GC Jr, Merchen NR, et al. (1995) In vitro fermentation of selected fibrous substrates by dog and cat fecal inoculum: influence of diet composition on substrate organic matter disappearance and short-chain fatty acid production. I Anim Sci 73, 1110-1122.

35. Vickers RJ, Sunvold GD, Kelley RL, et al. (2001) Comparison of fermentation of selected fructooligosaccharides and other fiber substrates by canine colonic microflora. Am J Vet Res 62, 609-615.

36. Dikeman CL, Murphy MR \& Fahey GC Jr (2006) Dietary fibers affect viscosity of solutions and simulated human gastric and small intestinal digesta. J Nutr 136, 913-919.

37. National Research Council (2006) Nutrient Requirements of Dogs and Cats. Washington, DC: National Academy Press.

38. AOAC (2006) Official Methods of Analysis, 17th ed. Arlington, VA: Association of Official Analytical Chemists.

39. AACC (1983) Approved Methods, 8th ed. St Paul, MN: American Association of Cereal Chemists.

40. Budde EF (1952) The determination of fat in baked biscuit type of dog foods. J Assoc Off Agric Chem 35, 799-805.
41. Prosky L, Asp N, Schweizer TF, et al. (1992) Determination of insoluble and soluble dietary fiber in foods and food products: collaborative study. J Assoc Off Anal Chem $\mathbf{7 5}$, 360-367.

42. Knapp BK, Parsons CM, Swanson KS, et al. (2008) Physiological responses to novel carbohydrates as assessed using canine and avian models. I Agric Food Chem 56, 7999-8006.

43. Staub H (1921) Examination of sugar metabolisms in human. Z Klin Med 91, 44-48.

44. Traugott K (1922) In reference to the reactions of blood sugar levels in repeated and varied types of enteral sugar increases and their significance in liver function. Klin Wochenschr 1, 892-894.

45. Shinoki A \& Hara H (2011) Dietary fructo-oligosaccharides improve insulin sensitivity along with the suppression of adipocytokine secretion from mesenteric fat cells in rats. $\mathrm{BrJ}$ Nutr 106, 1190-1197.

46. Reimer RA, Thomson AB, Rajotte RV, et al. (1997) A physiological level of rhubarb fiber increases proglucagon gene expression and modulates intestinal glucose uptake in rats. J Nutr 127, 1923-1928.

47. Thorburn A, Muir J \& Proietto J (1993) Carbohydrate fermentation decreases hepatic glucose output in healthy subjects. Metabolism 42, 780-785.

48. Jovanovic A, Leverton E, Solanky B, et al. (2009) The second-meal phenomenon is associated with enhanced muscle glycogen storage in humans. Clin Sci (Lond) $\mathbf{1 1 7}$, 119-127.

49. Venter CS, Vorster HH \& Cummings JH (1990) Effects of dietary propionate on carbohydrate and lipid metabolism in healthy volunteers. Am J Gastroenterol 85, 549-553.

50. Todesco T, Rao AV, Bosello O, et al. (1991) Propionate lowers blood glucose and alters lipid metabolism in healthy subjects. Am J Clin Nutr 54, 860-865.

51. Smeets-Peeters M, Watson T, Minekus M, et al. (1998) A review of the physiology of the canine digestive tract related to the development of in vitro systems. Nutr Res Rev 11, 45-69.

52. Pouteau E, Ferchaud-Roucher V, Zair Y, et al. (2010) Acetogenic fibers reduce fasting glucose turnover but not peripheral insulin resistance in metabolic syndrome patients. Clin Nutr 29, 801-807.

53. Weickert MO, Mohlig M, Koebnick C, et al. (2005) Impact of cereal fibre on glucose-regulating factors. Diabetologia $\mathbf{4 8}$, $2343-2353$

54. Weickert MO \& Pfeiffer AF (2008) Metabolic effects of dietary fiber consumption and prevention of diabetes. J Nutr 138, 439-442.

55. Juvonen KR, Purhonen AK, Salmenkallio-Marttila M, et al. (2009) Viscosity of oat bran-enriched beverages influences gastrointestinal hormonal responses in healthy humans. J Nutr 139, 461-466.

56. Hooda S, Matte JJ, Vasanthan T, et al. (2010) Dietary oat betaglucan reduces peak net glucose flux and insulin production and modulates plasma incretin in portal-vein catheterized grower pigs. J Nutr 140, 1564-1569. 